\title{
¿PROMUEVEN EL DERECHO URBANÍSTICO Y AMBIENTAL COLOMBIANO UN MODELO DE DESARROLLO URBANO SOSTENIBLE? ${ }^{1}$
}

\section{¿PROMOVEM O DIREITO URBANO E AMBIENTAL COLOMBIANO UM MODELO DE DESENVOLVIMENTO URBANO SUSTENTÁVEL?}

\section{Carlos Javier Velasquez ${ }^{2}$}

\section{Resumen}

Este artículo analiza la relación entre urbanismo y medio ambiente a partir de los desarrollos legales existentes en Colombia, con el objeto de determinar si como resultado de dicha aproximación, el país promueve un modelo de desarrollo urbano sostenible; objetivo de la nueva Agenda Global de Desarrollo (Objetivos de Desarrollo Sostenible) y de la Agenda Urbana Global (Urban III), con las cuales está comprometido. Para lograr dicho propósito, se llevó a cabo un levantamiento del estado del arte con la respectiva revisión, lectura reflexiva y crítica de diversas fuentes técnicas y jurídicas secundarias y terciarias (doctrina, jurisprudencia y normativa, en formato físico y electrónico), relievando las más importantes al respecto. Al final y como resultado del análisis elaborado, se obtuvo que, en efecto, el país apuesta, al menos de forma teórica, por el modelo de sostenibilidad urbana, y para ello dispone de una serie de mecanismos e instrumentos para su consecución, sin embargo, falla en su implementación. Las dificultades que condicionan la implementación son también relievadas en el análisis.

Palabras Clave: Urbanismo, Medio Ambiente, Derecho Urbanístico y Ambiental, Desarrollo Urbano Sostenible, Colombia.

\section{Resumo}

Este artigo analisa a relação entre o urbanismo e o meio ambiente a partir dos desenvolvimentos legais existentes na Colômbia, com o objeto de determinar se, como resultado desta relação, o país promove um modelo de desenvolvimento urbano sustentável; objeto da nova Agenda Global de Desenvolvimento (Objetivos do desenvolvimento sustentável) e da Agenda Urbana Global (Urban III), com as quais se comprometeu o país. Para obter o objetivo do artigo, um levantamento do estado da arte foi realizado com a reflexão, revisão reflexiva e crítica de diversas fontes jurídicas secundárias e terciárias (doctrinae, jurisprudência e normativas) em formato físico e eletrônico, ressaltando as mais importantes à respeito da matéria. Ao final, e como resultado da análise elaborado, obtuvo se que, em efeito, o país aposta, ao menos de forma teórica, pelo modelo de sustentabilidade urbana, e para isso existe uma série de mecanismos e instrumentos para sua consecução, sem embargo, erra em ele processo da implementação. As dificuldades da implementação, encontram-se integradas ao largo do documento e podem ser lidas.

\footnotetext{
${ }^{1}$ Este escrito hace parte de la investigación denominada: "La protección del medio ambiente urbano en Colombia", de la cual han surgido varias publicaciones entre libros y artículos científicos y de divulgación, así como artículos periodísticos y blogs de opinión.

2 Profesor Asociado de Tiempo Completo. Director del Centro de Estudios Urbano Regionales URBANUM. Director de la Maestría y Especialización en Derecho Ambiental y Urbano-Territorial. Doctor en Derecho, Universidad de Salamanca, España. E-mail: cvelasquez@uninorte.edu.co
} 
Palavras-chave: Urbanismo, Meio Ambiente, Direito Urbano e Ambiental, Desenvolvimento Urbano Sustentável, Colômbia.

\section{INTRODUCCIÓN: URBANISMO Y MEDIO AMBIENTE: UNA RELACIÓN INESCINDIBLE Y COMPLEJA}

Abordar la relación entre urbanismo y medio ambiente no es tarea fácil, sin embargo, no es por falta de aproximaciones, sino todo lo contrario, la dificultad puede ser quedarse corto.

Una primera imbricación viene dada por la existencia de un entorno natural previo a cualquier tipo de asentamiento o construcción; bien se sabe que la ciudad es considerada una de las principales creaciones humanas (Vinuesa Angulo, 2001; Reissmann, 1999; Camagni, 1999; Rees, 19996; Roca Cladera; 2002, Capel, 2002).

Desde una visión de sostenibilidad, el urbanismo, en tanto interdisciplina que estudia y gestiona las complejas dinámicas en la ciudad, toma en cuenta que la intervención antrópica en orden a hacer posible la vida en dicho espacio debe considerar, respetar y, ante todo, mejorar el entorno natural existente que, como se dijo, es previo a dicha intervención.

Lo anterior, según Camagni (1999: 266), es necesario, pero a la vez difícil, ya que, "la existencia de la ciudad supone una elección de fondo: la renuncia a un modelo de vida y de organización social basado en la integración hombre-naturaleza, por uno hombre-hombre; así como el abandono de las funciones de producción basadas en los factores tierra y trabajo, por funciones de producción basadas en el capital social fijo, la información y la energía".

Una segunda aproximación, planteada desde el urbanismo ${ }^{3}$, muestra que éste tiene por objeto de estudio a la ideación, planeación, decisión y gestión del territorio urbano, y desde esa mirada se han señalado una serie de atributos a considerar, uno de ellos, el ambiental ${ }^{4}$.

\footnotetext{
${ }^{3}$ A pesar de ser realidades diferentes, en Colombia el concepto de urbanismo fue confundido con el de ordenamiento del territorio. Lo anterior como consecuencia de la extrapolación realizada de contextos diferentes al nuestro, en particular del caso español, para dar forma a la Ley de desarrollo territorial, Ley 388 de 1997. En esta Ley se observa una mezcla desatinada de dos contenidos diferentes que dificultan cumplir con los objetivos de la norma. En este sentido, el artículo $3^{\circ}$ de la Ley es más que diciente: Artículo 30.- Función pública del urbanismo. El ordenamiento del territorio constituye en su conjunto una función pública, para el cumplimiento de los siguientes fines: 1. Posibilitar a los habitantes el acceso a las vías públicas, infraestructuras de transporte y demás espacios públicos, y su destinación al uso común, y hacer efectivos los derechos constitucionales de la vivienda y los servicios públicos domiciliarios. 2. Atender los procesos de cambio en el uso del suelo y adecuarlo en aras del interés común, procurando su utilización racional en armonía con la función social de la propiedad a la cual le es inherente una función ecológica, buscando el desarrollo sostenible. 3. Propender por el mejoramiento de la calidad de vida de los habitantes, la distribución equitativa de las oportunidades y los beneficios del desarrollo y la
} 
En virtud de lo anterior, a partir de la noción extensa de medio ambiente, el suelo, elemento de la esencia del urbanismo, lo es, asimismo, del medio ambiente. En ese sentido, la protección jurídica del ambiente incluye, indefectiblemente, la defensa del suelo y, en particular, del suelo urbano ${ }^{5}$.

En tercer lugar, cabría agregar que el urbanismo se ha movido entre dos visiones antagónicas sobre la forma o modelo predominante de ciudad: la ciudad tradicional europea ${ }^{6}$, densa y compacta; y la ciudad norteamericana, expansiva e irradiada en el territorio.

Hasta mediados del siglo XIX, la visión europea de ciudad tuvo apego principal por lo natural y por el entorno predominantemente ruralizado en el que se emplazó, así como por el

preservación del patrimonio cultural y natural. 4. Mejorar la seguridad de los asentamientos humanos ante los riesgos naturales. (Las subrayas son nuestras). Nótese como se señala en el título del artículo que se va a definir el urbanismo, pero se termina definiendo al ordenamiento del territorio.

${ }^{4}$ Ya se señaló que el ambiente o medio ambiente existe antes que cualquier acción o actuación antrópica sobre el territorio, por lo que el Urbanismo, a pesar de enfocarse en el hecho urbano, debe reconocerlo, respetarlo y tomarlo en cuenta como uno de sus más importantes atributos al momento desplegar sus ámbitos, técnicas y herramientas. El medio ambiente condiciona, sin duda, la vida en la ciudad y, en muchos casos, define su carácter, relaciones y los condicionantes mismos.

${ }^{5}$ Es por ello que desde la primera norma ambiental propiamente dicha de Colombia (Ley 23 de 1973), se introdujo el suelo como un elemento esencial del ambiente. El artículo $3^{\circ}$ de esta pieza legal señala: Se consideran bienes contaminables el aire, el agua y el suelo. Por su parte, el Código de los Recursos Naturales y de Protección del Ambiente, Decreto-Ley 2811 de 1974, incorpora un su artículo $8^{\circ}$ los factores que deterioran el ambiente, entre los cuales incorpora a.- La contaminación del aire, de las aguas, del suelo y de los demás recursos naturales renovables; b.- La degradación, la erosión y el revenimiento de suelos y tierras. Pero quizás lo más importante de este Código en relación con el suelo y el territorio es que tiene una parte completa dedicada a los suelos y las tierras. En efecto, la Parte VIII, en el cual se aloja Título II dedicado a los usos no agrícolas de la tierra, cuyo Capítulo I se denomina: De los Usos Urbanos, Habitacionales e Industriales. Importante es traer a colación lo que este Código señala en varios de sus artículos: Artículo 1870.- Se planeará el desarrollo urbano determinando, entre otros, sectores residenciales, cívicos, comerciales, industriales y de recreación, así como zonas oxigenantes y amortiguadoras y contemplando la necesaria arborización ornamental.

Artículo 188․- La planeación urbana comprenderá principalmente: 1.- La reglamentación de la construcción y el desarrollo de programas habitacionales según las necesidades de protección y restauración de la calidad ambiental y de la vida, dando prelación a las zonas con mayores problemas; 2.La localización adecuada de servicios públicos cuyo funcionamiento pueda afectar el ambiente; 3.- La fijación de zonas de descanso o de recreo y la organización de sus servicios para mantener ambiente sano y agradable para la comunidad. (Las subrayas son nuestras).

${ }^{6}$ Desde siempre ha sido así. La ciudad, según Benevolo, L. (1992), es una creación europea. Si nos remontamos en la rica historia y tradición europea, podremos encontrar cantidad de evidencias que permiten concordar con el autor; desde las ciudades prehelénicas que asumieron el trazado hipodámico, rectangular u ortogonal masificado por el griego Hipodamo de Mileto, pasando por la ciudad vitruviana, creada por el Arquitecto Italiano Marco Vitruvio, origen de las construcciones defensivas germanas (burgs), hasta las formas radiocéntricas de la época medieval y por supuesto, las ciudades industriales (en lo bueno y lo malo). Sin embargo, Benevolo atribuye el urbanismo moderno no a las primeras ciudades industriales, sino como la reacción más tardía que intenta corregir los desequilibrios causados por las profundas transformaciones del periodo de la industrialización. Señala que incluso en el tiempo presente, los conocimientos urbanísticos se aplican con un retraso con relación a los fenómenos que busca controlar. 
crecimiento controlado en forma y función. Por el contrario, la ciudad industrial, la ciudad fordista $y$, en adelante, modelos en esa dirección, se extendieron por el mundo, siendo los principales generadores de impactos ambientales de alcance global.

Si pensamos en los problemas globales, será forzoso concordar en que el cambio climático es el más importante de todos. Este problema tiene en el aumento de la concentración de gases de efecto invernadero ${ }^{7}$ a su principal detonante, y entre el 60 y el 70 por ciento de dichos gases se produce en las ciudades. Así las cosas, el principal problema ambiental global que es, a su vez, el principal problema global en general, corresponde a un asunto predominantemente urbano.

Por supuesto que con lo señalado hasta ahora no agotamos, ni mucho menos, la interminable lista de posibles relaciones entre urbanismo y medio ambiente, sin embargo, no es de la esencia de este trabajo traerlas todas. No obstante, hay una última de la mayor importancia que no podemos soslayar:

De acuerdo con Rees y Wackernagel (1996), la biocapacidad del planeta está limitada a 3.500 millones de personas, sin embargo, desde julio de 2017 el planeta alcanzó su habitante 7.500 millones (Country Meters, 2017, Worldometers, 2017). Lo anterior muestra que, hoy día, está más que duplicada la presión antrópica sobre el planeta para abastecer de recursos necesarios para vivir (y garantizar su renovabilidad) y para absorber los desechos resultantes del estilo de vida, predominantemente consumista ${ }^{8}$. De esos 7.500 millones de habitantes, desde 2007 más de la mitad vive en ciudades.

Lo anterior quiere decir que, siendo el elemento poblacional (en la ciudad) esencial para el urbanismo, es necesario que considere directrices claras y adecuadas de proyección, control y gestión demográfica en orden a propender por el mejoramiento de la calidad de vida urbana a

\footnotetext{
${ }^{7}$ No es este el espacio para ahondar en lo que es y cómo se comporta el cambio climático. De lo que sí no queda duda es que, paradójicamente, siendo un asunto de primer orden mundial, la mayoría de la población mundial desconozca de manera generalizada.

${ }^{8}$ La huella ecológica se define como la cantidad de territorio apropiada por las comunidades humanas (ciudades, regiones, estados) para mantener su grado de desarrollo y la satisfacción de sus necesidades de producción de bienes y servicios, así como la absorción de sus residuos. Ésta se mide en unidades territoriales por habitante, y se convierte en un planteamiento modificado del concepto ecológico conocido como capacidad de carga del territorio, referido a las limitaciones de un espacio natural concreto para mantener a una organización biológica determinada. Los informes actuales señalan que la huella ecológica global está en 1.8 mundos (wwf, 2012). De acuerdo con las organizaciones internacionales Global Footprint Network y New Economics Foundation, el planeta está agotando cada vez más rápido su presupuesto ambiental anual. Para 2017 el día de agotamiento fue el dos (2) de agosto, cinco meses antes de acabar el año (GFN, 2017).
} 
partir de regular el consumo de materias primas que el ambiente provee, así como gestionar adecuadamente los sobrantes que retornarán al entorno ${ }^{9}$.

Agotadas las conexiones anteriores surgen de inmediato preguntas: a.) ¿̇es o no importante estudiar los esfuerzos realizados para incorporar la constante ambiental en el modelo de desarrollo y, en particular, del desarrollo urbano?; b.) ¿es importante saber si Colombia ha realizado esfuerzos para dar respuesta a las problemáticas ambientales urbanas?; c.) ¿tiene Colombia un modelo de desarrollo urbano basado en criterios de sostenibilidad?; d.) ¿podrá Colombia cumplir con las metas establecidas en las agendas de desarrollo?; e. ¿promueven el derecho urbanístico y ambiental colombiano un modelo de desarrollo urbano sostenible?

Todos los interrogantes son, sin duda, importantes, pero en particular los tres últimos son el objetivo de este artículo, examinar si el derecho urbanístico y ambiental coadyuvan en la consecución de un modelo de desarrollo urbano bajo parámetros de sostenibilidad que den respuesta a las problemáticas ambientales glo-cales ${ }^{10} \mathrm{y}$, que, a su vez, encaminen el cumplimiento de las metas globales de desarrollo.

Las respuestas surgen en torno a esta investigación bibliográfica, ubicada a medio camino entre las tipologías de investigación jurídica de lege data y lege ferenda, ya que se parte del sistema jurídico vigente que se acepta, pero interpretado a partir de ciertas reglas de modificación ${ }^{11}$, lo que bien podría provocar una actualización al sistema dentro del sistema o abogar por su modificación ${ }^{12}$.

\footnotetext{
${ }^{9}$ Todo lo que se desecha hoy puede ser reusado o reutilizado. Desde hace más de tres décadas en muchos países desarrollados todo lo que se descarta es aprovechado a partir de lo que se denomina la gestión integral de residuos, que plantea desde la separación en la fuente y la recogida selectiva, pasando por el aprovechamiento de todo aquello que ha sido catalogado. Esa realidad, a pesar de ser ampliamente conocida, sigue siendo ajena a la realidad de países como Colombia.

${ }^{10}$ Glocalización es un término polisémico, el cual supone de forma general que, en un mundo global, en el que asistimos a una progresiva supresión de las fronteras a nivel económico, político y social, los seres humanos pueden disfrutar de su cotidianidad, pero entendiendo y asumiendo las dinámicas globales existentes.

${ }^{11} \mathrm{Al}$ respecto es interesante traer a colación los cinco parámetros o niveles con los que Manuel Atienza (1989) describe la racionalidad de la Ley. En ese sentido, una norma debe estar expuesta y sujeta a crítica si no cumple con todos y cada uno de los niveles de racionalidad. Estos son: a.) lingüístico: en cuanto a que el emisor (quien expide) debe ser capaz de transmitir con fluidez y claridad el mensaje al receptor (destinatario de la norma); b.) jurídico-formal: la nueva norma debe poder insertarse armoniosamente en un sistema jurídico dado; c.)pragmático: la conducta de los destinatarios debería adecuarse a lo prescrito en la norma; d.) teleológico: la norma debería poder alcanzar los fines para la cual fue expedida o promulgada; e.) ético: pues las conductas prescritas y los fines de la norma presuponen valores que tendrían que ser susceptibles de justificación ética.

12 De acuerdo con Latorre Latorre, V. (2012:129), "este tipo de investigaciones tienen un carácter descriptivo/prescriptivo, ya que no se pretende modificar el ordenamiento jurídico, sino interpretarlo
} 
Para alcanzar el propósito general planteado se realizó un levantamiento del estado del arte con la respectiva revisión, lectura reflexiva y crítica de diversas fuentes técnicas y jurídicas secundarias y terciarias (doctrina, jurisprudencia y normativa, en formato físico y electrónico) y se han analizado las más importantes teorías al respecto, lo cual permitirá llegar a las respuestas sobre los interrogantes planteados.

\section{TEORÍA DEL DESARROLLO Y DESARROLLO URBANO SOSTENIBLE}

Este segundo apartado se enfoca en precisar lo que el desarrollo es y, en particular, el desarrollo urbano sostenible, para lo cual es necesario, también, dedicar unas líneas al desarrollo sostenible ${ }^{13}$.

De acuerdo con Velásquez (2012: 41), las referencias al desarrollo son problemáticas y en la mayoría utilitaristas, ya que se identifican con variedad de acepciones, no siempre científicas o específicas, sino comunes, e incluso, genéricas ${ }^{14}$.

El Diccionario de la Real Academia de la Lengua Española (RAE, 2017), trae cuatro distintas acepciones del término ${ }^{15}$, una de ellas, en la dirección que se quiere hacer notar: la

mediando una adecuación a la realidad ofreciendo soluciones que den cuenta del universo de su aplicación".

${ }^{13}$ Lastimosamente la definición de los conceptos desarrollo, sostenibilidad, desarrollo sostenible resulta hoy algo complicada en la medida en que éstos han sido convertidos en vocablos de ligera utilización, incluso para definirse a sí mismos. Sin duda ha habido un sobreuso que ha llevado a casi eliminar el objetivo bienintencionado con el cual fue pronunciado hace ya algún tiempo, por ello, siempre es necesario volver al origen para no perderse en la maraña de connotaciones que soportan cualquier tipo de empresa o campaña y que en el fondo lo que buscan es restar fuerza e importancia a sus planteamientos. De acuerdo con García (2010:45) como definición (haciendo alusión al desarrollo sostenible) es de una vaguedad exasperante. En realidad, no es ninguna definición, sino una declaración de intenciones, un enunciado programático más que no la descripción de un proceso.

${ }^{14} \mathrm{Al}$ respecto es necesario traer a colación dos aspectos de importancia en relación con lo señalado: la primera es que el concepto de desarrollo nació gracias a su contrario, es decir, el no-desarrollo o subdesarrollo. Desde los 14 Puntos de Wilson (1918), el Pacto de Versalles (1919), la Carta del Atlántico (1941) o el Cuarto Punto de Truman (1949), se recalca el hecho de que existen pueblos no capacitados para dirigirse por sí mismos en las condiciones particularmente difíciles del mundo moderno (1919) o insuficientemente desarrolladas para su mejoramiento y crecimiento económico (1949). En ese sentido, su bienestar y el desenvolvimiento constituye una misión de la civilización. Por otro lado, y, en segundo lugar, es necesario señalar que, tanto el desarrollo, como el desarrollo sostenible son claros en su concepción original, sin embargo, han sido desfigurados por quienes pretenden señalar su inexistencia, haciendo alusión a la ambigüedad que se cierne sobre su comprensión. Basta ir a las fuentes originales para entender lo que significan, sin opinar para deformarlos. En el caso del desarrollo sostenible, el Informe Bruntland "Nuestro Futuro Común" o la declaración resultante de la Cumbre de Río y su Agenda 21 son claros.

${ }^{15}$ La primera señala de forma general que el desarrollo es acción y efecto de desarrollar o desarrollarse, a lo que desarrollar o desarrollarse es, según éste mismo libro, extender lo que está enrollado, deshacer un 
evolución progresiva de una economía hacia mejores niveles de vida. Por supuesto que esta definición merece toda crítica, pues pone excesivo acento en una visión económica, como si tratase solo de un asunto económico.

En términos generales, el desarrollo se asocia con la idea de bienestar, progreso, justicia social, riqueza material, mejora personal; imagen que ha sido sentada y sustentada por teorías múltiples a lo largo del tiempo.

De acuerdo con Rist (2002), el desarrollo es un concepto transitivo, no estático, por lo que ha tenido, y sigue teniendo, distintos períodos de evolución a partir de una multiplicidad de enfoques y aproximaciones. Si se toma como base el trabajo promovido por la Organización de las Naciones Unidas-ONU sobre el tema ${ }^{16}$, el desarrollo sostenible ha sido su último avance general ${ }^{17}$.

En particular, el desarrollo sostenible apareció en 1987 como resultado de los trabajos iniciados por la ONU ${ }^{18}$. En 1983, el Secretario General de la época, U-Thant, comisionó a la ex primera ministra de Noruega, Gro H. Bruntland, para conformar una Comisión Mundial encargada de preparar un informe sobre la relación entre medio ambiente y desarrollo, a partir de tres aspectos: a.) examinar los temas críticos y formular propuestas al respecto; b.) proponer nuevas formas de cooperación internacional para influir en la formulación de políticas globales sobre temas de desarrollo y medio ambiente; y, c.) promover niveles de involucración por parte de individuos, organizaciones, empresas y gobiernos sobre dicha relación.

Cuatro años después de iniciado el trabajo, la Comisión Mundial para el Medio Ambiente y el Desarrollo ${ }^{19}$, mejor conocida como Comisión Bruntland (en honor a su directora),

rollo. La segunda indica que el desarrollo es la combinación entre el plato y el piñón de la bicicleta, que determina la distancia que se avanza con cada pedalada. Como se ve, una definición deportiva del término. La tercera definición es automovilística, pues establece que el desarrollo es la relación entre la potencia y la velocidad en las marchas de la caja de cambios de un automóvil, determinada por la disposición de los engranajes.

16 Nos referimos a las distintas Cumbres y Conferencias para discutir sobre el desarrollo: desde una mirada económica en Bretton Woods (1944-1946), pasando por la dimensión humana en Estocolmo (1972) y la inclusión de la protección del entorno en Río de Janeiro (1992), hasta la integración de las dimensiones del desarrollo en la Cumbre del Milenio (2000) o Río +20 y la Cumbre Mundial sobre el Desarrollo Sostenible (2015).

${ }^{17}$ Cuenta de ello es también la Agenda Global de Desarrollo vigente que aboga por la consecución de 17 objetivos de desarrollo sostenible.

${ }^{18}$ No es posible olvidar que, desde su creación en 1941, con la firma de la Carta del Atlántico, la ONU proclamó su trabajo sostenido sobre las conocidas tres " $D$ ": a. Descolonización; b. Desarrollo y; c. Derechos Humanos. A fe que hasta hoy esa ha sido su consigna.

19 Solo 19 países fueron llamados a hacer parte de esta Comisión, en la cual, debido a su gran biodiversidad, participó Colombia. En nuestra representación asistió la directora del INDERENA, Margarita Marino de Botero. 
publicó el informe titulado: Nuestro Futuro Común, en el que se acuñó, abierta y explícitamente, el concepto de desarrollo sostenible: Nuestro futuro común pasa por alcanzar un desarrollo sostenible, este es el desarrollo económico que satisface las necesidades presentes pero que respeta los límites naturales impuestos por el medio, y que por tanto, garantiza la posibilidad a las generaciones futuras para satisfacer sus necesidades y alcanzar su desarrollo (Bruntland, 1987).

Se señala como fundamento de dicha visión, la imposición de ciertas restricciones a los sistemas económicos en relación con el medio que sustenta su actividad, sin embargo, se deja en claro que la sostenibilidad no implica una economía estancada ${ }^{20}$. Lo anterior ha llevado, necesariamente, a distinguir entre crecimiento y desarrollo: el crecimiento (económico), como aumento cuantitativo de la riqueza material, no puede sostenerse indefinidamente en un mundo finito; el desarrollo económico, como mejora sustancial de la calidad de vida puede ser sostenible si, en efecto, toma en cuenta la cantidad de recursos consumidos (Daly, 1990; Bifani, 1999, p. 106).

Si bien el desarrollo sostenible pone un acento especial en la inclusión de la gestión y protección del entorno, por supuesto que va mucho más allá que dicha protección. De esa forma, además de la protección del sistema natural, integra otros aspectos como la preocupación por la calidad de vida (no solo el aumento de los ingresos), la igualdad entre las personas en el presente (incluida la lucha contra la pobreza) y la equidad intergeneracional (los seres del futuro merecen un medio ambiente que sea, como mínimo, tan bueno como el que tenemos actualmente, si no mejor) (Velásquez 2012: 75).

\section{El desarrollo urbano sostenible}

Las preguntas sobre las cuales gira este subtítulo son: ¿puede implementarse el desarrollo sostenible en las ciudades?; ¿cómo se traslada este modelo a las ciudades?

De acuerdo con De acuerdo con Tamayo-Lora (2006: 16), la ciudad es prima facie insostenible, pues sustituye recursos por asfalto y desborda de manera desmesurada la capacidad de carga del territorio. Para Moreno Molina (2008) el desarrollo sostenible aplicado al ámbito urbano no es nuevo, sino que más bien tomó aire a partir de la penetración de la

\footnotetext{
${ }^{20}$ Este fue el paradigma de las denominadas corrientes ecoeficientistas de la economía, muy populares en la década de los 70 del siglo pasado. Estas corrientes llegaron a proponer estancar el desarrollo económico, el desarrollo 0 , teniendo en cuenta que todas las actividades económicas generan impactos ambientales.
} 
corriente humanista en el urbanismo internacional de los años sesenta del siglo pasado, la cual apenas ahora ha logrado convertirse en una apuesta teórica con cierto grado de relevancia interdisciplinar. Lo que no admite discusión hoy, es que la sostenibilidad aplicada al hecho urbano es fundamental para el mantenimiento global ${ }^{21}$. Según Rees y Wackernagel (1996:43), la batalla por la sostenibilidad se ganará en las ciudades.

Así las cosas, la mirada transectorial que implica la sostenibilidad es hoy una exigencia al hablar de la ideación, planeación y gestión de las ciudades; lo anterior, a pesar de que, en principio, no pareciera ser el escenario para poner a prueba sus postulados ${ }^{22}$.

En términos generales, el desarrollo urbano sostenible refiere a la puesta en acción, con carácter transversal, holístico y transectorial, de los postulados que sustentan el modelo de desarrollo sostenible llevado al ámbito de las realidades urbanas ${ }^{23}$. Lo anterior pasa, entonces, por varios supuestos:

1. Este modelo implica una combinación entre sostenibilidad fuerte y visión glocal: lo anterior significa aceptar que las medidas que se tomen deben partir de la consideración de que el capital natural es insustituible y, por tanto, se debe impedir su degradación o desaparición. Por otro lado, los problemas que afectan la sostenibilidad urbana se abordan mejor desde el ámbito local, pensando, como ya se señaló, en el mantenimiento global;

\footnotetext{
${ }^{21} \mathrm{El}$ mantenimiento global es uno de los enfoques de la sostenibilidad, y tiende a centrar el cúmulo de las preocupaciones del desarrollo sostenible hacía un tipo de desarrollo ecológicamente sostenible, es decir, donde la máxima preocupación del desarrollo gira en torno a la idea de preservar las condiciones ecológicas necesarias para mantener la vida humana sobre el planeta con una visión holística y de largo plazo. Este parece ser el enfoque arraigado en la mayoría de los expertos sobre la materia, a juzgar por la abundante literatura coincidente. La visión ecológica del desarrollo sostenible gira en torno a dos premisas básicas: la primera enfatiza en los límites ecológicos y la imposibilidad de crecimiento continuo en un espacio finito; la segunda destaca la solidaridad con las generaciones futuras $y$, por lo tanto, la necesidad de preservar la base de los recursos naturales y ambientales, de modo que dichas generaciones tengan la posibilidad de disponer de ellos y decidir sobre su bienestar: el principio de equidad intergeneracional (Velásquez, 2010).

${ }^{22}$ Se señala que en principio no parecería ser el escenario ideal, ya que, al ser una manufactura, no le son aplicables los principios de equilibrio y racionalidad que pregona la sostenibilidad, como sí ocurre, en cambio, en un sistema natural. No obstante, y por el hecho de ser un sistema abierto antropizado, compuesto por subsistemas complejos, se requieren abordajes holísticos y transectoriales para ver el funcionamiento del sistema de manera integral.

${ }^{23}$ Que tantas y tan diferentes son las realidades urbanas de este mundo actual. Desde la tradicional ciudad compacta y sus múltiples formas urbanas históricas (las formas regulares hipodámicas, las vitruvianas, ciudades jardín), pasando por ciudades lineales, la ciudad expansiva o fordista norteamericana, hasta las nuevas realidades urbana de hoy: megalópolis, ciudades región, ciudades globales y hasta ciudades sostenibles desde su primera piedra (los proyectos de Dongtan en China, Massdar en Abu Dhabi y Songdo en Korea).
} 
2. La ciudad debe ser entendida como un ecosistema: ya se aludió a la complejidad que ello significa al asimilar el principal espacio artificial construido a un sistema natural, equilibrado e integral. Al respecto, el estudio de la ciudad desde las ciencias exactas y naturales y sus aportes, son fundamentales para el logro de este propósito;

3. La ciudad no puede ser vista como cualquier ecosistema, sino como uno abierto: las dinámicas, imaginarios, problemáticas y demás aspectos no terminan con el perímetro urbano; para la sostenibilidad urbana es tan importante el espacio construido y consolidado, como la relación entre la ciudad y el territorio circundante (hinterland, zona suburbana, rural, región, etc.) proveedor de materias primas y sumidero de sus remanentes;

4. Se debe reconocer que la principal característica de la ciudad es su complejidad y, por tanto, no hay dinámicas o problemas lineales, sino problemáticas complejas que requieren soluciones complejas. En ese sentido, la ciudad debe ser entendida y gestionada de manera integral, holística, y transectorial;

5. Se reafirma el hecho de que no existe modelo ideal de ciudad, la sostenibilidad no aboga por un modelo ideal, sino por un ideal que se mejora de forma permanente (to keep going continous(y). En ese sentido, las ciudades deben evolucionar, pero también pueden involucionar; las ciudades pueden ir hacia adelante, pero también estancarse o incluso, morir ${ }^{24}$

6. En la ciudad es necesario el desarrollo económico, pues constituye la base necesaria para las inversiones frente al cierre de las brechas sociales y la mejorar de la calidad del entorno;

7. El modelo propone otra forma de tomar de decisiones, de manera que se rompan las barreras tradicionales que separan municipios colindantes o al interior de una misma administración, cambiando actitudes y fomentando la participación pública y la responsabilidad en la toma de decisiones;

8. El modelo propugna por la planificación estratégica para el desarrollo como la herramienta principal, en donde el medio (la planificación) y el fin (el desarrollo), se vean como un conjunto integral de interacciones y correspondencia mutuas; transparente, novedosa y articulada a las agendas globales.

24 El caso paradigmático en el país es Bogotá. Después de varias buenas administraciones llenas de ejecutorias, mucha cultura ciudadana, participación y sentido de pertenencia por la ciudad, los bogotanos han escogido varios gobiernos sin claridad sobre lo fundamental. La Bogotá de hoy involucionó por lo menos 20 años en relación con el sitial en el cual la dejaron quienes la administraron, 12 años atrás. 


\section{Las Agendas globales para el desarrollo}

Hoy día, el desarrollo urbano sostenible no es solo una proclama, sino un objetivo para la acción, así lo señalan las agendas globales para el desarrollo.

La principal agenda global está contenida en los Objetivos de Desarrollo Sostenible-ODS, en los cuales la sostenibilidad urbana aparece incorporada en varios de ellos, pero, específicamente, en el ODS 11, el cual planteó: "lograr que las ciudades y los asentamientos humanos sean inclusivos, seguros, resilientes y sostenibles" (ONU, 2015).

Así las cosas, y para cumplir con el ODS 11 se definieron 7 ambiciosas metas ${ }^{25}$ para mejorar la realidad de los seres humanos en las zonas de mayor concentración. Por su parte, se aprobó la denominada: Agenda Urbana Global, alcanzada en la reunión Hábitat III de octubre de 2016 en Quito, Ecuador" ${ }^{26}$. En dicha reunión se aprobó la "Declaración sobre Ciudades y Asentamientos Humanos Sostenibles para Todos", en la cual se establecieron 175 puntos como línea orientadora del desarrollo urbano global para los próximos veinte años.

La nueva Agenda Urbana aboga por la igualdad de derechos y oportunidades y el respeto por las libertades fundamentales de todos los habitantes de las ciudades y asentamientos humanos y exhorta a una nueva manera de hacer urbanización, a partir de principios claros, legislaciones urbanísticas robustas, procesos de planificación urbana acordes con las necesidades de la población y a partir de novedosos mecanismos de financiación, contribuyendo a satisfacer el pleno ejercicio del derecho a la ciudad.

Para alcanzar dicho ideal, la nueva agenda urbana establece seis atributos sobre el modelo de ciudad ${ }^{27}$, entre ellas, el de alcanzar una ciudad sostenible, entendida como una

\footnotetext{
25 a.) reducir los déficits cuantitativos y cualitativos de vivienda; b.) mejorar los servicios urbanos básicos o esenciales; c.) promover la movilidad sostenible; d.) alcanzar un urbanismo sostenible; e.) proteger y conservar el patrimonio cultural y natural; f.) gestionar el riesgo y la adaptación/mitigación al cambio climático; y, g.) llevar a cabo una adecuada y correcta gestión ambiental urbana en varios aspectos: g.1.) reducir la contaminación y mejorar la calidad del medio ambiente urbano; g.2.) mejorar la cantidad y cualidad del espacio público, en particular de zonas verdades y sitios de recreación; g.3.) reducir la precariedad y, g.4.) empoderar y corresponsabilizar a la ciudadanía en la consecución de las metas planteadas.

26 Hábitat III viene a ser la continuación del trabajo adelantado por la ONU sobre el desarrollo de las ciudades. En la primera conferencia, en Vancouver (Canadá) en 1976, se creó la institucionalidad encargada del tema: la Fundación de las Naciones Unidas para el Hábitat y los Asentamientos Humanos (FNUHAH). 20 años después (1996) se celebró la segunda Conferencia en Estambul (Turquía) y en ésta se alcanzó la "Agenda Hábitat", con más de 100 compromisosy 600 recomendaciones sobre el desarrollo urbano, con una mirada sostenible.

27 Las otras tipologías de ciudad que establece la Agenda Urbana son: la ciudad compacta, la ciudad inclusiva, la ciudad resiliente, la ciudad participativa y la ciudad segura, las cuales definió así:
} 
ciudad que, "planifica su futuro medioambiental, social y económico a través de soluciones innovadoras que generan prosperidad y respetan los recursos naturales" (Documento Nueva Agenda Urbana, ONU-Hábitat 2016).

Dicho lo anterior, cabe preguntarse ¿qué hay en Colombia?, ¿qué se está realizando para guiar la acción hacia la consecución de las metas señaladas?; desde el derecho, ¿se promueve la consecución de dichos propósitos?

\section{¿PROMUEVEN EL DERECHO URBANISTICO Y AMBIENTAL UN MODELO DE DESARROLLO URBANO SOSTENIBLE EN COLOMBIA?}

Cabría acotar la amplitud de la pregunta que guía esta parte, en el sentido de que el enfoque de sostenibilidad se presenta desde la vertiente ambiental del modelo y, por ello, el ejercicio consiste en determinar qué tanto la consideración ambiental está presente en las normas urbanísticas y qué tanto la consideración de los asuntos urbanos en las normas ambientales colombianas. Por supuesto que, desde un análisis exhaustivo de sostenibilidad, faltaría considerar los aspectos económicos y humanos que hacen parte inescindible del modelo.

Lo primero que habría de señalar es que en Colombia la visión normativa plurisectorial entre protección ambiental y urbanismo existe de tiempo atrás, casi coincidente con la aparición misma de las primeras normas en cada una de las respectivas materias ${ }^{28}$.

\footnotetext{
La ciudad inclusiva, es una ciudad en la que todos sus habitantes, de las generaciones presentes y futuras sin discriminación de ningún tipo, puedan disfrutar libremente de todos los espacios físicos, políticos y sociales, ejerciendo de igual manera el derecho a una vivienda adecuada y a tener acceso a los bienes y servicios públicos;

La ciudad compacta, es una ciudad planificada para favorecer el uso mixto y público del suelo, valorizando los espacios dentro del perímetro urbano y favoreciendo la movilidad colectiva;

La ciudad resiliente, es una ciudad capaz de resistir y de recuperarse rápidamente de los riesgos humanos, sociales y medioambientales, minimizando el impacto y la vulnerabilidad de sus ciudadanos; La ciudad participativa, es una ciudad en la que se promueve la libre participación de todos sus habitantes, generando un sentido de pertenencia no excluyente, que mejora la cohesión social y las interacciones culturales, como base de sociedades plurales, multiculturales y vivas;

La ciudad segura, es una ciudad que no tiene fronteras para sus ciudadanos, donde los espacios públicos son la clave para construir comunidades plurales y pacíficas, evitando la estigmatización de grupos sociales (ONU-HÁBITAT, 2016)

${ }^{28}$ Hacemos hincapié inicialmente en las normas de protección ambiental, ya que estas surgieron con carácter general, años antes de las normas urbano-territoriales.
} 
La inclusión de las consideraciones urbanas en las normas ambientales inició con la expedición del Código los Recursos Naturales-CNRN (Decreto-Ley 2811 de 1974), el cual, a pesar de haber sido expedido bajo una mirada predominantemente naturalista (conservacionista), alcanzó a anticipar la situación de los entornos urbanos al señalar en varios de sus apartes, prescripciones explícitas relacionadas con el desarrollo urbano y su incidencia en la protección ambiental.

Los artículos 187 a 190, todos ellos ubicados en el Capítulo I del Título II titulado: "de los usos no agrícolas de la tierra", así como los 192 y 193 del Capítulo Il de ese mismo título sobre: los Usos en trasporte: aeropuertos, carreteras, ferrocarriles, dan cuenta de ello.

Los primeros establecieron los usos urbanos, habitacionales e industriales, en torno a los que debía planearse el desarrollo urbano, determinando, entre otros aspectos, la ubicación de sectores residenciales, cívicos, comerciales, industriales y de recreación; así como, las debidas zonas oxigenantes y amortiguadoras y la necesaria arborización ornamental.

En particular, el artículo 189 señaló que las industrias, que por su naturaleza pudieran causar deterioro ambiental, debían estar situadas en zonas adecuadas, de manera tal que no causasen daño o molestia a los habitantes de sectores vecinos, ni sus actividades $y$, agrega, que deberá tener en cuenta la ubicación geográfica, así como la dirección de vientos y demás características del medio ambiente.

El artículo 190, por su parte, señala que se tomarán las medidas necesarias para que las industrias existentes en zonas inadecuadas se trasladen a otras en las que se llenen las exigencias anteriores $y$, entre tanto, se dispondrá lo necesario para que causen las menores molestias a los vecinos.

Por su parte, los artículos 192 y 193 señalaron preceptos relacionadas con la incidencia ambiental en la planeación urbana. El 192 establece que esta planeación tendrá en cuenta las tendencias de expansión de las ciudades, con la intención de localizar adecuadamente la infraestructura estratégica, en particular la aeroportuaria, dado que son fuente sensible de producción de ruido y emanaciones difícilmente controlables. El 193 determina que, tratándose de construcción de carreteras y vías férreas, se deberán tomar todas las precauciones para no causar deterioro ambiental con alteraciones topográficas, emanaciones y/o ruidos de los vehículos, entre otros varios aspectos.

Más adelante el mismo CRNR, en la Parte V del Libro II, sobre: los recursos del paisaje y de su protección (arts. 302 a 304) añade otras disposiciones. El art. 302 establece de forma clara que: "la comunidad tiene derecho a disfrutar de paisajes urbanos y rurales que contribuyan a su 
bienestar físico y espiritual. Se determinarán los que merezcan protección" (las subrayas son nuestras).

En consonancia con lo anterior, el 304 define que, "en la realización de obras, las personas o entidades urbanizadoras, públicas y privadas, procurarán mantener la armonía con la estructura general del paisaje" (las subrayas son nuestras).

De esa manera, como antes se señaló, a pesar de que el CNRN tiene una marcada orientación naturalista, fue capaz de acoger la relación entre protección ambiental y acción urbanística en todos aquellos aspectos de desarrollo urbano que pudieran afectar. Obviamente, se nota precariedad en la forma de abordar la relación, recibiendo un tratamiento integral, pero si se quiere, puntual y acotado; entendible para aquel momento.

Con la expedición del CNRN se dio inicio a un proceso amplio de reglamentación sobre cada una de las cuestiones incluidas, las cuales examinaron la necesidad de incorporar disposiciones de índole ambiental en los procesos de crecimiento y concentración de población en entornos urbanos.

Dadas las limitaciones de espacio, sólo nos detendremos en algunos ejemplos más relevantes. Así, nos parece pertinente reparar en las normas sobre protección del paisaje.

Al respecto hay que estarse a lo dispuesto en el decreto 1715 de 1978, decreto antiguo, pero aún vigente. En su art. 1 señala que, "El Instituto Nacional de los Recursos Naturales Renovables y del Ambiente-INDERENA (Órgano ambiental de la época), determinará los paisajes que merezcan protección en consonancia con lo dispuesto en el CNRN".

Los paisajes a los que alude y que son objeto de regulación y protección, incluyen los presentes o existentes en entornos urbanos, sin embargo, y a pesar de la referencia explícita a paisajes urbanos, no se conoció hasta 1997 instrumento normativo alguno que detallase las condiciones para dicha tipología de paisaje, o las medias adecuadas para su protección y/o conservación ${ }^{29}$.

El mencionado decreto en su artículo 4, prohíbe explícitamente, "deformar o alterar elementos naturales como piedras, rocas, peñascos, praderas, árboles, con pintura o cualquier otro medio para fines publicitarios o de propaganda en general". De conformidad con lo anterior, el artículo 5 establece que, "la alteración perjudicial o antiestética de paisajes naturales es un factor que deteriora el ambiente" y, por tanto, debe ser sancionado.

\footnotetext{
${ }^{29}$ Nos referimos a la Ley 388 de 1997, mejor conocida como Ley de Desarrollo Urbano-Territorial, en la cual se señala la obligación a municipios, distritos o áreas metropolitanas de localizar las áreas de reserva para la protección y defensa del paisaje.
} 
En el otro sentido, esto es, la inclusión de la protección ambiental en los asuntos urbanos, hay que estarse a lo dispuesto en la primera ley urbana, promulgada en la década de los setenta del siglo pasado; nos referimos a la ley 61 de 1978, mejor conocida como Orgánica de Desarrollo Urbano.

La Ley 61 estableció las orientaciones necesarias para la intervención del Estado en la mejora de las condiciones económicas, sociales, culturales y ecológicas de las ciudades colombianas (las subrayas son nuestras) ${ }^{30}$. Dicha ley creó un instrumento operativo para la consecución de sus objetivos, el denominado Plan Integral de Desarrollo, el cual obligó a Municipios con más de 100.000 habitantes a planificar su desarrollo urbano, tomando en consideración de manera primordial, el equilibrio entre las diversas regiones del territorio y entre las zonas rurales, urbanas y de conservación ecológica.

Más adelante, el cruce entre la realidad urbanística y ambiental recibió renovado impulso a partir del año de 1986, cuando se dieron cambios políticos y normativos en la configuración del aparato político-administrativo del estado. En ese año se promulgó el Acto Legislativo No. 1, el cual dinamizó un significativo proceso de descentralización, teniendo a la planificación como una de sus principales herramientas.

El acto legislativo fue reglamentado, a su vez, por la ley 11 de 1986, con la cual se organizó el Régimen Municipal Colombiano en aspectos claves como el señalamiento de las obligaciones para la creación de municipios ${ }^{31}$, y lo más destacado para efectos de este trabajo, el fortalecimiento del proceso de planificación del desarrollo municipal, el cual reconoció la realidad ambiental como parte esencial.

A su vez, la ley 11 fue reglamentada por un decreto con fuerza de ley ${ }^{32}$, el 1333, mejor conocido como Código de Régimen Municipal, el cual determinó lo relativo a planes y programas de desarrollo económico y social, así como las obras públicas necesarias para la

\footnotetext{
${ }^{30}$ Sin embargo, esta Ley no pudo desplegar sus efectos jurídicos como se esperaba, ya que fue declarada inexequible un año después por la Corte Suprema de Justicia, en Sentencia de 14 de agosto de 1979, señalándose vicios en el trámite de aprobación. De acuerdo con Morcillo Dosman (2007:97), los errores en la ley pasaron, en realidad, por el otorgamiento amplio y sin claridad de facultades al Presidente de la República para expedir normas sobre dichos asuntos.

${ }^{31}$ Estableció regulaciones en Asociaciones de Municipio; Juntas Administradoras Locales; división del territorio municipal en Comunas y Corregimientos; participación comunitaria en los servicios públicos; organización de entidades descentralizadas municipales, etc., y se otorgaron facultades extraordinarias al ejecutivo, para codificar la normatividad dispersa sobre el municipio.

${ }^{32}$ Lo anterior quiere decir que, a pesar de que es en forma un acto administrativo, tiene alcance de ley. Este tipo de figuras son comunes en los estados presidencialistas, donde el gobierno, con base en facultades dadas por el legislativo o en estados de excepción, se comporta con un cuerpo legislativo.
} 
ejecución de estos. En dichos planes estuvo también, de forma inequívoca, la dimensión ambiental.

n particular, el artículo 31 de este decreto-ley, hoy derogado por el 138 numeral 70 de la ley 388 de 1997 señaló: "se entiende por ley orgánica de desarrollo urbano, al conjunto de normas generales que permitan orientar las instituciones jurídicas y la intervención del Estado hacia el propósito fundamental de mejorar las condiciones económicas, sociales, culturales y ecológicas de las ciudades, de suerte que sus habitantes, mediante su participación justa y equitativa de los beneficios y obligaciones de la comunidad, puedan alcanzar el progreso máximo de su persona y su familia en todos los aspectos de la vida humana o sea en lo moral, lo cultural, lo social y lo físico" (las subrayas son nuestras).

Para corroborar lo anterior, el artículo 32, aún vigente, determina que, "el desarrollo de las áreas urbanas se regulará dentro de una política nacional de equilibrio entre las diversas regiones del territorio y entre las zonas rurales, urbanas y de conservación ecológica..." Asunto, claro y conciso.

El siguiente desarrollo legal en materia urbano-territorial fue la Ley 9 de 1989, la cual, a nuestro juicio, pone punto de consolidación definitivo a la Planificación del Desarrollo Municipal, inicialmente con una visión predominantemente económico-social, pero siempre provista de un componente urbano-territorial, y permeadas ambas, por la defensa ambiental del territorio.

La Ley 9 se encargó de agrupar los temas, todavía para entonces separados, en torno al concepto de desarrollo municipal, especialmente, en lo atinente al desarrollo urbano y la reglamentación de los usos del suelo. Como en su momento ocurrió con el Código de los Recursos Naturales, la ley catapultó la expedición de un sinnúmero de reglamentos, encaminados a lograr condiciones óptimas para el desarrollo de las ciudades y sus áreas de influencia.

Nuevamente, y debido a limitaciones de espacio, sólo podremos considerar alguna de esas reglamentaciones. En ese sentido, nos parece pertinente reparar en las normas sobre formulación y adopción de los planes de desarrollo municipal.

El decreto 2400 de 1989 reglamentó lo relacionado con los planes de desarrollo municipal. Este decreto reconoce, por ejemplo, que los conceptos de espacio público y medio ambiente se encuentran estrechamente vinculados, y que, por tanto, deben ser organizados e 
incluidos en la planificación para un mejor cuidado y disfrute de los ciudadanos. En ese sentido, recuerda que existen acciones legales para ser garantizar la integridad de dicha relación ${ }^{33}$.

Con los antecedentes preconstitucionales mencionados se llegó a 1991, año en el cual se expidió la nueva Constitución Política del país. La Carta Política abrió un renovado espacio para el desarrollo urbano bajo criterios de sostenibilidad, pues consagró un amplio elenco de derechos, entre los cuales reconoció a los colectivos y del medio ambiente, situando en un mismo plano de protección los relacionados con el respeto y mejora del ambiente y el desarrollo armónico del territorio y la defensa de la integridad del espacio público (Arts. 79 y 82, respectivamente).

Cabe anotar que los cambios estuvieron respaldados por procesos políticos globales, como la realización de la Cumbre de la Organización de las Naciones Unidas para el Medio Ambiente y el Desarrollo (Cumbre de Río), la cual, a pesar de haberse llevado a cabo en junio de 1992, fue preparada de tiempo atrás, con activa participación por parte de Colombia.

El principal resultado de dicha Cumbre fue su declaración de principios, la cual sentó las bases para alcanzar la plena inserción de la protección ambiental en el modelo de desarrollo y señaló, que el tipo de desarrollo necesario para mejorar la calidad de vida de la población debe tomar en consideración que el crecimiento económico tiene límites insoslayables, los cuales vienen impuestos por la capacidad de recuperación del medio, como garantía de equidad intergeneracional ${ }^{34}$.

Fue bajo esa mirada que se expidió la ley 99 de 1993 o ley marco ambiental ${ }^{35}$, la cual introdujo importantes consideraciones en relación con la utilización del suelo y el ordenamiento ambiental del territorio y, en lo relacionado con la gestión ambiental urbana, generó situaciones encaminadas a garantizar la protección del medio ambiente en el ámbito urbano. De entre los artículos que esta ley introduce destacan, al menos, dos: los artículos 5.10 y 66.

\footnotetext{
${ }^{33}$ Acciones de tipo administrativo, como los amparos policivos y/o acciones judiciales, como la acción popular, en ese momento reglamentadas en el artículo 1005 del Código Civil.

${ }^{34}$ El Principio de Equidad Intergeneracional que se desprende de la idea de sostenibilidad es aquel que pone a pensar y actuar a las generaciones presentes sobre el compromiso de trabajar día a día para dejarle a los que vienen un planeta mejor que el que encontraron, con la intención de que sean los habitantes del futuro los que decidan qué hacer con su vida en la tierra y sobre todo, intentar mejorar las condiciones de vida, pensando en los que vendrán después. Por supuesto que este ha sido un compromiso humano vital, globalmente incumplido.

${ }^{35}$ Para afianzar aún más el hecho de que la Cumbre de Río fue fundamental para la consolidación de la noción de sostenibilidad en el país, tenemos que el art. 1 de la Ley 99 de 1993, el cual se dedicó a los Principios Generales de la Política Ambiental Colombia señala en su numeral 1, que los principios contenidos en la declaración resultante de la Cumbre, son, a su vez, principios de la política ambiental colombiana.
} 
El primero otorgó al Ministerio la competencia para expedir la política ambiental aplicable a los entornos urbanos ${ }^{36}$; el segundo, por su parte, da a distritos, municipios y áreas metropolitanas, cuya población urbana fuere igual o superior a un millón de habitantes, las competencias necesarias para: "ejercer las mismas funciones ambientales atribuidas a las Corporaciones Autónomas Regionales ${ }^{37}$, en lo que fuere aplicable al medio ambiente urbano".

Al año siguiente (1994) los impulsos normativos continuaron. En ese sentido, se expidieron las leyes 136, sobre organización y funcionamiento de los municipios y la 152 u orgánica de la planificación social, económica y ambiental; la cual señala los principios, procedimientos y mecanismos para la formulación de los planes nacional y territoriales de desarrollo. Ambas establecieron la necesidad de incluir, con carácter transversal, la protección del ambiente al momento de planificar el desarrollo ${ }^{38}$.

Pero, sin duda, el esfuerzo normativo terminó de cuajar en 1997, año en el cual se expidió la norma, todavía vigente, sobre desarrollo urbano-territorial: la ley $388^{39}$.

Esta ley complementa el panorama planificador establecido por la Constitución Política ${ }^{40}$ y reglamentado de manera principal en la Ley 152 de 1994, pero encaminado hacia la

\footnotetext{
${ }^{36}$ Tarea que se ha venido haciendo y que desembocó en la expedición de la importante Política de Gestión Ambiental Urbana, de noviembre de 2008. A pesar de que dicho documento señala que es parte de la política de desarrollo urbano, quienes la elaboraron y publicaron fueron el Consejo Nacional Ambiental y las demás autoridades ambientales del SINA. No está de más recordar que para aquella época el Ministerio del ramo era el de Ambiente, Vivienda y Desarrollo Territorial, por lo que urbanismo y medio ambiente estaban en cabeza del mismo ente rector.

${ }^{37}$ De acuerdo con el art. 23 de la Ley 99 de 1993: Las Corporaciones Autónomas Regionales son entes corporativos de carácter público, creados por la ley, integrados por las entidades territoriales que por sus características constituyen geográficamente un mismo ecosistema o conforman una unidad geopolítica, biogeográfica o hidrogeográfica, dotados de autonomía administrativa y financiera, patrimonio propio y personería jurídica, encargados por la ley de administrar, dentro del área de su jurisdicción, el medio ambiente y los recursos naturales renovables y propender por su desarrollo sostenible, de conformidad con las disposiciones legales y las políticas del Ministerio del Medio Ambiente.

${ }^{38}$ El literal h) del art. 3 de la Ley 152 de 1994, sobre los principios generales de la planificación del desarrollo, señala que, "para posibilitar un desarrollo socioeconómico en armonía con el medio natural, los planes de desarrollo deberán considerar en sus estrategias, programas y proyectos, criterios que les permitan estimar los costos y beneficios ambientales para definir las acciones que garanticen a las actuales y futuras generaciones una adecuada oferta ambiental. Por su parte, en el art. 4 de esta misma ley se lee que todo plan de desarrollo (nacional y territorial) debe establecer con claridad las estrategias y políticas en materia económica, social y ambiental que guiarán la acción del Gobierno para alcanzar los objetivos y metas que se hayan definido;

39 La ley 388 de 1997 modificó, casi en su totalidad, a la 9 de 1989. Solo quedó un 20\% de esta última vigente.

${ }^{40}$ La Constitución Política de 1991 establece un capítulo completo, el 2 del título XII, a la planeación del desarrollo (artículos 339 a 344),
} 
planificación del espacio físico y territorial a escala municipal ${ }^{41}$ a través de los Planes de Ordenamiento Territorial-POT, en los cuales en los cuales hay una decisiva previsión relacionada con la protección ambiental.

La ley está plagada de alusiones y consideraciones en las cuales se deja ver que, al menos desde un punto de vista teórico y normativo, el modelo urbano-territorial acogido incluye al desarrollo sostenible y la protección ambiental como sus pilares. Veamos, grosso modo, lo que incorpora.

Nada más comenzar, en su art. 1, señala dentro de sus objetivos los siguientes:

"2. El establecimiento de los mecanismos que permitan al municipio, en ejercicio de su autonomía, promover el ordenamiento de su territorio, el uso equitativo y racional del suelo, la preservación y defensa del patrimonio ecológico y cultural localizado en su ámbito territorial y la prevención de desastres en asentamientos de alto riesgo, así como la ejecución de acciones urbanísticas eficientes...

...3. Garantizar que la utilización del suelo por parte de sus propietarios se ajuste a la función social de la propiedad y permita hacer efectivos los derechos constitucionales a la vivienda y a los servicios públicos domiciliarios, y velar por la creación y la defensa del espacio público, así como por la protección del medio ambiente y la prevención de desastres" (las subrayas son nuestras).

Por su parte, al establecer lo relacionado con los principios que guían el desarrollo urbano-territorial (art. $2^{\circ}$ ), incorpora los relacionados con la función social y ecológica de la propiedad y la prevalencia del interés general sobre el particular.

El art. 3 eleva a función pública el urbanismo y señala que dicha función se ejerce para el cumplimiento de los siguientes fines:

"2. Atender los procesos de cambio en el uso del suelo y adecuarlo en aras del interés común, procurando su utilización racional en armonía con la función social de la propiedad, a la cual le es inherente una función ecológica, buscando el desarrollo sostenible;

3. Propender por el mejoramiento de la calidad de vida de los habitantes, la distribución equitativa de las oportunidades y los beneficios del desarrollo y la preservación del patrimonio cultural y natural; $y$,

4. Mejorar la seguridad de los asentamientos humanos ante los riesgos naturales (las subrayas son nuestras).

Pero, además, el art. 10 de la ley determina que en la elaboración y adopción de los $\mathrm{POT}^{42}$, los municipios y distritos deben tener en cuenta un conjunto de determinantes, las

\footnotetext{
${ }^{41}$ Sin embargo, en la actualidad para la planificación del espacio físico no solo existen los POT, pues a éstos se le ha añadido la obligación de ordenar el espacio físico metropolitano y departamental por cuenta de los Planes Estratégicos Metropolitanos de Ordenamiento Territorial-PEMOT y los Planes de Ordenamiento Departamental-POD y, entre todos estos, debe existir la debida armonía y articulación.

${ }^{42}$ Art. 9 Ley 388 de 1997. Plan de Ordenamiento Territorial. El plan de ordenamiento territorial que los municipios y distritos deberán adoptar en aplicación de la presente Ley, al cual se refiere el artículo 41 de
} 
cuales, son las normas de superior jerarquía al interior de dichos instrumentos. La primera y más extensa de dichas determinantes, es la relacionada con la conservación y protección del medio ambiente, los recursos naturales, así como con la prevención de amenazas y riesgos naturales ${ }^{43}$.

En adición a lo anterior, y para cerrar este esbozo de imbricación entre urbanismo y medio ambiente en el desarrollo urbano, la ley 388 en su art. 24, sobre el procedimiento de formulación y adopción de los POT, incluye la obligación de obtener un concepto de la/s autoridad/des competente/s en los asuntos ambientales de la ordenación del territorio. Señala que dicho concepto es vinculante y que, de no existir o no estar conforme con las normas ambientales, no podrá ser aprobado ${ }^{44}$

Las normas provenientes de la ley general de desarrollo urbano han catapultado, a su vez, la promulgación de otras que ponen de presente la aplicación particular y práctica de la sostenibilidad urbana, adoptando o, al menos, configurando un tipo de modelo al respecto. Tal

la Ley 152 de 1994, es el instrumento básico para desarrollar el proceso de ordenamiento del territorio municipal. Se define como el conjunto de objetivos, directrices, políticas, estrategias, metas, programas, actuaciones y normas adoptadas para orientar y administrar el desarrollo físico del territorio y la utilización del suelo. Los planes de ordenamiento del territorio se denominarán:

${ }^{43}$ La ley 388 define como el contenido de la determinante ambiental de los POT a los siguientes asuntos: a) Las directrices, normas y reglamentos expedidos en ejercicio de sus respectivas facultades legales, por las entidades del Sistema Nacional Ambiental, en los aspectos relacionados con el ordenamiento espacial del territorio, de acuerdo con la Ley 99 de 1993 y el Código de Recursos Naturales, tales como las limitaciones derivadas de estatuto de zonificación de uso adecuado del territorio y las regulaciones nacionales sobre uso del suelo en lo concerniente exclusivamente a sus aspectos ambientales; b) Las regulaciones sobre conservación, preservación, uso y manejo del medio ambiente y de los recursos naturales renovables, en las zonas marinas y costeras; las disposiciones producidas por la Corporación Autónoma Regional o la autoridad ambiental de la respectiva jurisdicción, en cuanto a la reserva, alindamiento, administración o sustracción de los distritos de manejo integrado, los distritos de conservación de suelos, las reservas forestales y parques naturales de carácter regional; las normas y directrices para el manejo de las cuencas hidrográficas expedidas por la Corporación Autónoma Regional - la autoridad ambiental de la respectiva jurisdicción; y las directrices y normas expedidas por las autoridades ambientales para la conservación de las áreas de especial importancia ecosistémica; c) Las disposiciones que reglamentan el uso y funcionamiento de las áreas que integran el sistema de parques nacionales naturales y las reservas forestales nacionales: d) Las políticas, directrices y regulaciones sobre prevención de amenazas y riesgos naturales, el señalamiento y localización de las áreas de riesgo para asentamientos humanos, así como las estrategias de manejo de zonas expuestas a amenazas y riesgos naturales.

${ }^{44}$ Art. 24 núm. 1. El proyecto de Plan se someterá a consideración de la Corporación Autónoma Regional o autoridad ambiental correspondiente, para su aprobación en lo concerniente a los asuntos exclusivamente ambientales, dentro del ámbito de su competencia de acuerdo con lo dispuesto por la Ley 99 de 1993 y en especial por su artículo 66, para lo cual dispondrá de treinta (30) días; sólo podrá ser objetado por razones técnicas y fundadas en los estudios previos. Esta decisión será, en todo caso, será apelable ante el Ministerio del Medio Ambiente. 
es el caso de la ley 1083 de 2006, sobre Planeación Urbana Sostenible, nombre en verdad sugestivo, en medio de la escasez de referencias directas sobre el tema.

Independientemente de la importancia que reviste el hecho de contar con normas de rango legal que intenten regular este asunto, lo cierto es que dicha norma equivocó su título, pues solo refiere a uno de los temas transversales del desarrollo urbano sostenible, la movilidad, el cual, además, se articula con insuficiencia y debilidad a los demás temas relacionados con la sostenibilidad urbana.

La 1083 está plagada de errores y asuntos a medio regular, sin embargo, y sin proponérselo (como ya recalcamos), anuncia un tema y aborda otro: reconoce la importancia de regularizar la movilidad urbana a fin de lograr ciudades sostenibles, señalando, además, que ello contribuiría a que las esferas económica, social y ambiental se encuentren en justo equilibrio.

Además de lo anotado, tiene la virtud de atar a instrumentos jurídicos vinculantes la forma de organizar dicha movilidad y asigna competencias ineludibles, en la mayoría de los casos, con plazos de cumplimiento concretos. Sin embargo, no se observa claramente la manera como dichas normas serán aplicadas, además de que es fácilmente perceptible que no logran superar la sectorialidad, primer y más importante escollo por superar, sí se quiere avanzar en la sostenibilidad urbana.

La indeterminación, amplitud y, sobre todo, falta de voluntad política para adoptar las medidas y ejercer las acciones prácticas para consolidar la sostenibilidad en la ciudad colombiana han llevado a que la realidad diste mucho de la teoría general y los desarrollos normativos, pues éstos existen.

Lo anterior se ve reflejado en la información que sobre sostenibilidad urbana se produce en el país. Así tenemos, por ejemplo, la encuesta comparada en 14 ciudades de la Red de Ciudades Cómo Vamos ${ }^{45}$, muestra como el medio ambiente es un asunto marginal en la agenda política y ciudadana de las ciudades en el país. En general la satisfacción de los ciudadanos con la gestión de las autoridades locales en favor del medio ambiente no pasa del $38 \%$, mientras que hay ciudades como Cartagena, Ibagué o Cali, donde no pasa del $15 \%$.

\footnotetext{
${ }^{45}$ Como se señaló, esta Red la conforman 14 ciudades entre grandes e intermedias del país: Bogotá, Medellín, Cali, Cartagena, Medellín, Barranquilla, Bucaramanga Metropolitana, Valledupar, Ibagué, Pereira, Manizales y Yumbo. Anualmente, en las 14 ciudades donde hace presencia la Red se encuestan a más de 12 mil personas en temas relaciones con su calidad de vida urbana.
} 
Lo anterior resulta paradójico si tomamos en consideración que solo 2 de cada 10 personas ven como preocupante la baja arborización, la mala calidad del aire, la incorrecta disposición de residuos o la contaminación sonora y visual (Red Ciudades Cómo Vamos 2014).

Además de lo anterior, está la información dada por el gobierno nacional sobre el cumplimiento de los Objetivos de Desarrollo del Milenio, en particular en lo relacionado con el objetivo No. $7^{46}$. Este informe señala que el país pudo cumplir con la meta de áreas reforestadas, pero que en todo lo demás, con preponderancia en las carencias ambientales urbanas, está lejos de contar con una buena situación.

Por señalar un par de datos tenemos que el $40 \%$ de los municipios del país no tienen alcantarillado y que solo el $35 \%$ de las aguas residuales municipales son tratadas (2'100.000 personas no tienen servicio sanitario en sus viviendas) (PNUD, 2014).

Por último, si bien constituye un avance operativo que debe ser reconocido y elogiado, el Índice de Calidad Ambiental Urbana ${ }^{47}$ implementado en diciembre de 2013, como

\footnotetext{
${ }^{46}$ El séptimo Objetivo de Desarrollo del Milenio (ODM7) buscaba: "garantizar la sostenibilidad del medio ambiente". Lo anterior, estaba atado al aspecto ambiental, indisociable pero distinguible, del desarrollo sostenible: responder a las necesidades humanas presentes, sin destruir la capacidad del medio ambiente para atender estas necesidades en el largo plazo (equidad ambiental intergeneracional).

${ }^{47}$ Este es un interesante e importante índice implementado por el Ministerio de Ambiente y Desarrollo Sostenible, el cual analizó nueve ciudades de más de 500.000 habitantes y otros 32 centros urbanos de menor tamaño de Colombia, en relación con los siguientes aspectos: a.) Superficie de área verde por habitante: Número de metros cuadrados de espacios verdes urbanos por habitante en la unidad espacial de referencia en el período de tiempo; b.) calidad de aire: estado de la concentración promedio anual de contaminantes "criterio": Material Particulado (PM10 y PM2.5) y Ozono, en un tiempo de exposición determinado; c.) Calidad de agua superficial: estado de las corrientes superficiales de la ciudad, con base en las mediciones de un conjunto de cinco o seis parámetros básicos; d.) Porcentaje de áreas protegidas urbanas incluidas en el POT con plan de manejo ambiental aprobado por la Autoridad Ambiental; e.) Porcentaje de residuos sólidos aprovechados: Residuos sólidos que están siendo aprovechados (incluyendo todo tipo de aprovechamiento) respecto a la totalidad de los residuos generados Cantidad de residuos sólidos por habitante dispuestos en relleno sanitario: Cantidad de los residuos sólidos dispuestos en relleno sanitario en un período de tiempo determinado; f.) Porcentaje de suelos de protección urbanos incluidos en el POT con conflictos de uso del suelo: Relación entre la extensión de suelos de protección urbanos incorporados en el POT, con ocupación o uso de suelo que no corresponde con la aptitud de los mismos, sobre el área total de suelo de protección incorporado en el POT para el perímetro urbano; g.) Espacio público efectivo por habitante: Relación entre la extensión de las zonas de espacio público efectivo en el perímetro urbano y la población que habita esta área; h.) Porcentaje de longitud de sistemas alternativos y masivos de transporte: Relación entre la longitud de los sistemas alternativos y masivos de transporte existentes en una ciudad, sobre la longitud de la red vial total; i.) Porcentaje de población urbana expuesta a ruido por encima de los niveles permisibles: Relación entre la población afectada por niveles de presión sonora por encima de los máximos permitidos, sobre el total de la población urbana (cabecera); j.) Población urbana que participa en gestión ambiental: Relación entre las personas que participan en procesos de gestión ambiental en las áreas urbanas (planificación, ejecución, evaluación y seguimiento) con referencia al total de población; k.) Población urbana vinculada a estrategias de educación ambiental: número de personas que han estado vinculadas en alguna estrategia de Educación Ambiental desarrollada por la Autoridad Ambiental y/o el ente territorial, con referencia a
} 
consecuencia de la ejecución del plan de acción de la Política sobre Gestión Ambiental Urbana (MVDT, 2008), muestra que el estado de la gestión ambiental y, por ende, del medio ambiente de las ciudades del país es crítico; ninguna de las ciudades medidas alcanzó una calificación satisfactoria ${ }^{48}$.

Todo lo anterior solo demuestra un profundo desconocimiento y culturización del ciudadano y una desatención ¿consciente?, de las autoridades por un asunto que, al parecer no representa votos a la clase dirigente.

\section{CONCLUSIONES}

Frente al interrogante que motivó la realización de este trabajo habría que señalar que, en efecto, Colombia tiene algunos avances normativos frente a la consecución de un modelo de desarrollo urbano sostenible a partir de la imbricación entre el derecho ambiental y urbanístico. Como se señaló, las disposiciones existen de tiempo atrás y, además, contienen prescripciones claras y operativas para alcanzar dichos propósitos.

Así mismo, se reconoce como herramienta principal para dicho propósito a la planificación del desarrollo por cuenta de diversos tipos de planes. Sin embargo, esta planificación se encuentra a medio camino entre la planificación del desarrollo y el uso de algunas herramientas incorporadas en la moderna planificación para el desarrollo.

En relación con lo anterior tenemos que, el país ha abordado una visión pluritemporal, entiende la existencia de múltiples escalas, tiene una planificación intersectorial y sectorial y se ha articulado a la visión global del desarrollo, sin embargo, no cuenta con mecanismos idóneos para armonizar dichas exigencias.

\footnotetext{
la población total urbana; I.) Población urbana localizada en zonas de amenaza alta: Relación entre la cantidad de población que habita en zonas de amenaza alta, frente a la totalidad de la población urbana (perímetro urbano); m.) Porcentaje de superficie construida con criterios de sostenibilidad: Relación entre la superficie de edificaciones que cuentan con licencia de construcción y que incorporan criterios ambientales frente a la superficie total de edificaciones construidas de forma legal; y, n.) Consumo residencial de agua y energía por habitante: Consumos per cápita de agua y energía, para uso doméstico dentro de las áreas urbanas.

48 De acuerdo con el estudio lo más crítico es la falta de información ambiental. La mayoría de las ciudades reportan porcentajes negativos en sus cumplimientos, ya que, precisamente, no cuentan con información que reportar. Así las cosas, el nivel de incertidumbre de esta medición es alta para ciudades como Cúcuta (24,1 por ciento) y Soledad (30,4 por ciento), donde se desconocen indicadores de superficies de área verde, calidad del aire y donde otros ítems como calidad del agua y la población que participa de la gestión ambiental no resultaron válidos para este modelo nacional.
} 
Muchos son los asuntos que quedan por incluir y mejorar. La preservación y mejora ambiental y del patrimonio cultural, así como la gestión del riesgo, siguen siendo algo marginales en la visión del desarrollo urbano. A pesar de que la ley las establece como determinantes de superior jerarquía al momento de planificar los entornos urbanos.

Así mismo, el creciente centralismo político-administrativo del país, apegado a una visión profundamente desarrollista ha hecho mella en la autonomía de los entes locales y en sus capacidades para planear su desarrollo conforme a sus propias problemáticas y dinámicas. La visión preponderante es la de una administración central avasallante, que solo rumia sobre megaproyectos con altos impactos ambientales y sociales, sobre los cuales no se miden con claridad sus efectos.

Los procedimientos y técnicas de la planificación no son diferenciados y no es lo mismo un proceso desplegado desde Bogotá, la cual cuenta con recursos económicos, humanos, técnicos, institucionales, de convocatoria e interlocución; que los planes formulados por municipios de categoría inferiores, quienes se ven en ascuas para cumplir, pues trabajan con los mismos tiempos, pero con recursos económicos, humanos y técnicos escasos y con claras debilidades institucionales ${ }^{49}$.

Pero en todo esto también los entes locales tienen responsabilidad. Los Planes de Ordenamiento Territorial de primera generación fueron un fracaso ${ }^{50}$. Luego de finalizada su visión de largo plazo muy poco fue lo ejecutado; en el caso de ciudades como Barranquilla solo se ejecutó en un 2\%. Pero es que, además, luego de 12 años aún hay 919 municipios de 1122 sin un Plan de Ordenamiento actualizado y hay algunos sin plan.

Por su parte la gestión urbana sigue siendo caótica, los problemas de la ciudad se abordan sectorialmente y entre instancias de diferentes administraciones hay roces en vez de coordinación, complementariedad o subsidiariedad. Se construyen de manera permanente soluciones lineales para problemas complejos, lo cual termina avivándolos.

Algo que resulta curioso es que es posible hacerles seguimiento a los problemas locales a través de la prensa para advertir que cíclicamente el periodismo se ocupa de ellos en un largo

\footnotetext{
${ }^{49}$ De los 1122 municipios que tiene Colombia, el 85\% son considerados como de sexta categoría, es decir la categoría más baja, solo para municipios pequeños con alta dependencia a los presupuestos y las políticas del gobierno nacional.

${ }^{50}$ Se les denomina POT de primera generación a aquellos expedidos entre los años 1998 y 2001 y que terminaron su vigencia al vencimiento del componente general de largo plazo, es decir, 12 años después. Quiere decir que entre los años 2012 y 2014 vencieron los POT del país, los cuales deben estar revisados y actualizado a día de hoy, cosa que no ha pasado.
} 
lapso de tiempo, aparecen, desaparecen y luego vuelven a aparecer. Es decir, se dice que se solucionan, pero nunca se solucionan.

Las ciudades pequeñas e intermedias tienen problemas de ciudades grandes, la movilidad el primero de ellos. Sin mallas viales adecuadas, sin educación para el ciudadano, sin transportes públicos de calidad, sin estímulos para las formas alternativas de movilidad, sin recuperación de las viejas mallas viales de las ciudades, sin obras de infraestructura vial acordes con las especificaciones y dinámicas del siglo XXI, este problema va de mal en peor.

\section{REFERENCIAS BIBLIOGRÁFICAS}

Benevolo L. (1992). Orígenes del Urbanismo Moderno. Traducción de Floreal Mazia Celeste Ediciones. Madrid, España

Camagni, R. (1999) El Desarrollo Urbano Sostenible: Razones y Fundamentos de un Programa de Investigación. En: Cuadernos de Economía Española No. 80. Págs. 266-289

Daly, H. (1990). "Sustainable Development: From Concept and Theory to Operational Principles", en Population and Development Review, Vol. 16.

Diario El tiempo (2015). Las mejores y peores ciudades del país en calidad ambiental. artículo periodístico aparecido en la edición del día jueves 30 de octubre de 2015

Ministerio de Ambiente y Desarrollo Sostenible (2013). I Índice de Calidad Ambiental Urbana. Bogotá, Colombia

Ministerio de Ambiente, Vivienda y Desarrollo Territorial (2008). Política de Gestión Ambiental Urbana. Bogotá, Colombia

Moreno, A. M. (2009). Urbanismo y Medio Ambiente: las claves jurídicas del planeamiento urbano sostenible. Madrid, España. Editorial Universidad Carlos III de Madrid y Tirant lo Blanch

Morcillo, P. (2008) Derecho Urbanístico Colombiano. Editorial Temis. Bogotá, Colombia

Moreno, M. (2010). Génesis, Evolución y Tendencias del Paradigma del Desarrollo Sostenible. México, México. Editorial Porrúa

Programa de la Organización de las Naciones Unidas para el Desarrollo-PNUD (2014). Informe sobre el cumplimiento de los objetivos de desarrollo del milenio Colombia. Bogotá, Colombia

Santacruz, M. (2009). El Espacio del Desarrollo. Cali, Colombia. Universidad Autónoma de Occidente

Latorre, V. (2012). Bases Epistemológicas para la Investigación Jurídica. Valencia, España. Editorial Tirant Lo Blanch 
Lora-Tamayo, M. (2006). Derecho Urbanístico y Medio Ambiente. Madrid, España. Editorial Dykinson

Organización de Naciones Unidas (1987) Informe de la Comisión Mundial sobre el Medio Ambiente y el Desarrollo: Nuestro Futuro Común. Asamblea General de la ONU, documento A/42/427 de 4 agosto. Nueva York, Estados Unidos

Rist, G. (2002). El Desarrollo: Historia de una Creencia Occidental. Madrid, España. Editorial Catarata, Universidad Complutense de Madrid

Velásquez, C. (2010). Ciudad y Desarrollo Sostenible. Barranquilla, Colombia. Editorial Universidad del Norte-Ecoe Ediciones

Velásquez, Carlos. (2010). Evolución de la Política Nacional Ambiental en materia de desarrollo urbano sostenible. En: Libro Diez años de Investigación Jurídica y Sociojurídica en Colombia: balances desde la Red Sociojurídica. Tomo II. Ediciones Universidad de la Sabana-Universidad del Rosario. Bogotá, Colombia. Págs. 66-106. ISBN: 978-958-12-0277-5

Velásquez, C. (2008). ¿Avanza el desarrollo urbano sostenible en Colombia?: análisis de la Ley 1083 de 2006, sobre planeación urbana sostenible. Ponencia presentada en el VI Encuentro de la Red de Centros y Grupos de Investigación Jurídica y Socio Jurídica de Colombia. Paipa, Boyacá, Colombia.

World Wide Fund for Nature. (2012). Living Planet Report 2012 WWF. Banson Prod. Cambridge

Wackernagel E. \& Rees W. (1996). Our Ecological Footprint, Reducing Human Impact on the Earth. New society Publishers, Gabiola Islands BC, Bioregional Series.

Zuluaga, D. (2015) El derecho al paisaje en Colombia: consideraciones para la definición de su contenido, alcance y límites. Temas de Derecho Administrativo 6. Editorial Universidad Externado de Colombia. Bogotá, Colombia

Trabalho enviado em 27 de fevereiro de 2018.

Aceito em 25 de abril de 2018. 